\title{
Implementasi Metode Topsis pada Sistem Penunjang Keputusan Pemilihan Wedding Venue
}

\author{
Iga Fitria Ekawati ${ }^{1}$ Latipah $^{2}$ \\ 1,2 Jurusan Sistem Informasi, Fakultas Ilmu Komputer, Universitas Narotama Surabaya \\ ${ }^{1}$ Igafitri96@gmail.com, ${ }^{2}$ latifahrifani@gmail.com
}

\begin{abstract}
Abstrak
Dalam mempersiapkan acara pernikahan, dibutuhkan tenaga serta waktu yang cukup panjang agar acara yang di selenggarakan dapat berjalan sesuai dengan keinginan. Impian dalam merencanakan acara pernikahan, selalu di impikan oleh setiap pasangan. Surabaya merupakan salah satu kota dengan padatnya penduduk. Kondisi tersebut menimbulkan masalah dikarenakan jika pasangan yang akan menyelenggarkan acara pernikahan tidak memiliki lahan yang cukup untuk menyelenggarakan acara penikahan, maka pasangan tersebut perlu melakukan observasi jasa persewaan gedung (Wedding Venue) di Surabaya. Mengumpulkan Informasi terkait Wedding Venue diperlukan waktu yang cukup lama. Dari permasalahan yang didapatkan, maka dibangunnya suatu sistem rekomendasi pemilihan wedding vеnue agar memudahkan pihak penyewa dalam menentukan venue yang sesuai. Salah satu algoritma yang dapat digunakan untuk memberikan rekomendasi dengan banyaknya kriteria serta alternatif adalah (Technique For Order of Preference by Similarity to Ideal Solusition (TOPSIS). TOPSIS merupakan algoritma dengan hasil perangkingan alternatif tertinggi memiliki jarak terpendek dari solusi ideal positif dan jarak terjauh dari solusi ideal negatif denga kriteria yang digunakan dalam pemilihan Wedding Venue antara lain Biaya Sewa, jumlah daya tampung, fasilitas serta jarak lokasi pihak penyewa dengan gedung.. Untuk merancang sistem rekomendasi ini, digunakan metode pengembangan SDLC yang memiliki alur terurut pada setiap tahapan yang dilakukan. Hasil yang didapatkan melalui dua tahapan pengujian yaitu pengujian fungsional dan non-fungsional. Pada pengujian fungsional dilakukan teknik pengujian black box dan Hasil yang diperoleh sebesar $100 \%$. Pengujian non-fungsional dilakukan untuk melakukan perbadingan dari hasil output rekomendasi sistem dengan output perhitungan manual. Hasil yang didapatkan dari pengujian non-fungsional sebesar $100 \%$.
\end{abstract}

Kata kunci : sistem pendukung keputusan, wedding venue, TOPSIS

\section{Pendahuluan}

Pernikahan adalah hal yang menjadi moment impian bagi setiap pasangan yang menjalankannya. Adanya jasa Wedding Organizer, Event Organizer, dan Wedding Palnner menjadi salah satu alasan bahwa setiap pasangan membutuhkan bantuan untuk mempersiapkan dan merencanakan acara pernikahan yang sesuai dengan impian mereka. Keinginan memiliki pernikahan yang sesuai dengan mimpi, mengharuskan mereka untuk mempersiapkan biaya yang cukup besar. Karena dengan melibatkan jasa layanan Wedding Organizer, Event Organizer atau Wedding Planner membutuhkan biaya yang lebih. Penyebab terjadinya kendala dalam mempersiapkan pernikahan ialah dibutuhkan waktu yang lebih untuk mengumpulkan informasi terkait lokasi, catering, tempat persewaan pakaian, souvenir, cetak undangan, jasa dokumentasi, serta dekorasi untuk menunjang acara yang akan diselenggarakan.

Surabaya merupakan salah satu Ibu Kota terbesar di Indonesia. Surabaya dibagi menjadi empat titik wilayah yaitu Surabaya Selatan dengan delapan titik Kecamatan, Surabaya Barat dengan enam titik Kecamatan, Surabaya Timur dengan tujuh titik Kecamatan, Surabaya Utara dengan lima titik
Kecamatan dan Surabaya Pusat dengan empat titik Kecamatan(Surabaya, 2015). Jumlah Penduduk di Surabaya pada bulan Januari 2019 sebanyak 3.095.026 jiwa dengan jumlah penduduk terpadat adalah Kecamatan Tambaksari dan yang paling sedikit jumlah penduduknya adalah Kecamatan Bulak (Sipil, 2019). Padatnya penduduk di Surabaya menyebabkan banyaknya tempat tinggal hanya memiliki luas lahan yang tidak cukup besar. Sehingga, untuk melangsunhgkan acara pernikahan dengan banyakanya jumlah tamu undangan sangat tidak efektif jika melakukan acara pernikahan pada lokasi tempat tinggal.

Di Surabaya terdapat jasa Wedding Vепие sebanyak 20 jasa persewaan, diantaranya terdapat 2 Wedding Venue di Surabaya Utara dan Pusat, 7 Wedding Venue di Surabaya Timur, 6 Wedding Venue di Surabaya Selatan dan 3 Wedding Venue di Surabaya Barat. Dengan melakukan riset bahwa usia pernikahan sering terjadi di usia 20-30 tahun setiap tahunnya. Kriteria yang dipertimbangkan dalam pemilihan Wedding Venue antara lain jumlah daya tampung Vепиe, biaya sewa Venue, fasilitas yang disediakan serta jarak antara lokasi pihak penyewa dengan Venue. 
Untuk mendapatkan informasi terkait rekomendasi gedung yang sesuai, maka digunakanlah metode TOPSIS. TOPSIS sering digunakan karena memiliki perhitungan yang menggunakan alternatif terbaik terpilih karena memiliki jarak terdekat dari solusi ideal positif dan jarak terjauh dari solusi ideal negatif.

Permasalahan mengenai informasi terkait adanya jasa Wedding Venue di Surabaya masih dilakukan secara manual. Sehingga, diperlukan waktu yang lama untuk menemukan lokasi yang sesuai dengan pihak penyewa. Karena banyaknya jumlah tempat yang menyediakan jasa Wedding Venue di Surabaya, maka perlu adanya sistem yang dapat memberikan informasi dan rekomendasi yang tepat untuk menentukan lokasi pernikahan yang sesuai dengan impian mereka. Dengan adanya sistem tersebut, diharapkan dapat membantu pengguna agar lebih efisien dan efektif merancakan acara pernikahan yang sesuai dengan budget dan dapat di rencangakan secara mandiri.

\section{LANDASAN TEORI}

\subsection{Sistem Pendukung Keputusan}

Sistem Pendukung Keputusan (SPK) merupakan sistem berbasis computer interaktif yang membantu pengambilan keputusan dengan memanfaatkan data dan model untuk menyelesaikan suatu masalah (Hidayati, 2017) Sistem Pendukung Keputusan adalah sistem yang mampu memberikan kemampuan pemecahan masalah maupun kemampuan pengkomunikasoan untuk masalah dengan kondisisemi terstruktur dan tidak terstruktur(Ningsih, Dedih and Supriyadi, 2017). Dengan landasan terori yang telah dijelaskan, maka dapat disimpulkan bahwa Sistem Pendukung Keputusan sering digunakan untuk membantu dalam memberikan solusi atas suatu masalah secara terstruktur maupun tidak terstruktur.

\subsection{Wedding Venue}

Wedding adalah sebuah kosa kata dalam Bahasa inggris yang berarti sebuah pernikahan. Pernikahan merupakan suatu bentuk kegiatan yang dilakukan secara sakral dan bermakna dalam setiap keyakinan. Dalam undang-undang No.1 tahun 1974 pasal 1 menyebutkan bahwa pernikahan dalam ikatan lahir batin antara seorang pria dengan seorang wanita sebagai suami-istri dengan tujuan membentuk keluarga (rumah tangga) yang bahagia dan kekal berdasarkan Tuhan Yang Maha Esa(Widjaja, 2015). Venue adalah sebuah kosa kata dalam Bahasa Inggris yang berarti tempat. Maka, Wedding Venue merupakan suatu tempat yang menyediakan layanan untuk mendukung sebuah acara pernikahan.
2.3 Technique For Others References by Similiarity to Ideal Solusition

Technique For Others References by Similiarity to Ideal Solusition (TOPSIS) merupakan metode yang mengukur jarak positif dan negative dari banyaknaya alternative keputusan. Metode TOPSIS adalah metode dengan konsep dimana solusi alternative harus memiliki jarak Euclidean terpendek dari solusi ideal positif dan memiliki jarak jauh dari solusi ideal negatif(Paypas, Dewi and Brata, 2019).

Pada dasarnya untuk mendapatkan solusi dengan metode TOPSIS ialah sebagai berikut (Iswari, Arini and Muslim, 2019) :

1. Membuat matriks ternormalisasi :

$\mathrm{r}_{\mathrm{ij}}=\frac{\mathrm{x}_{\mathrm{ij}}}{\sqrt{\sum_{\mathrm{i}=1}^{\mathrm{m}} \mathrm{x}_{\mathrm{ij}}^{2}}}$

Dimana : $i=1,2,3, \ldots m$; dan $j=1,2,3, \ldots n$;

$\mathrm{m}$ merupakan jumlah alternative yang akan dievaluasi dan Xij merupakan nilai rating yang cocok dengan alternatif ke-1terhadap kriteria ke-1.

2. Membuat matriks keputusan yang ternormalisasi dan terbobot :

$\mathrm{y}_{\mathrm{ij}}=\mathrm{w}_{\mathrm{i}} \mathrm{r}_{\mathrm{ij}}$

$\mathrm{W}$ adalah pangkat yang memiliki nilai positif untuk atribut keuntungan (benefit) dan nilai negative untuk atribut biaya (cost).

3. Menentukan matriks solusi ideal postif $\left(\mathrm{A}^{+}\right)$ dan negatif $\left(\mathrm{A}^{-}\right)$:

$A^{+}=\left(y_{1}+y_{2}+\cdots+y_{n}\right)$;

$A^{-}=\left(y_{1}-y_{2}-\cdots-y_{n}\right)$;

Rumus (3) digunakan untuk perhitungan soulusi ideal positif, dengan menggunakan nilai maximal dari kategori keuntungan (benefit) dan menggunakan nilai minimal dari kategori biaya (cost). Begitu sebaliknya, rumus (4) digunakan untuk perhitungan solusi ideal negative dengan menggunakan nilai ermaximal dari kategori biaya (cost) dan nilai minilai dari kategori keutungan (benefit).

4. Menentukan jarak antara Ai terhadap solusi ideal positif dan ideal negatif :

$D_{i}^{-}=\sqrt{\sum_{j=1}^{n}}\left(y_{i j}-y_{i^{+}}\right) 2$

$D_{i}^{+}=\sqrt{\sum_{j=1}^{n}}\left(y_{i j}-y_{i^{-}}\right) 2$

Rumus (5) dan (6) digunakan mengukur jarak antara solusi ideal positif dengan solusi ideal negatif.

5. Mengurutkan peringkat setiap alternatif :

$V_{i}=\frac{D_{i}^{-}}{D_{i}^{-}+D_{i}^{+}}$ 
Rumus (7) digunakan untuk menentukan alternatif terbaik dari jarak terdekat dari solusi ideal positif dan jarak terjauh dari solusi ideal negatif.

\section{METODEOLOGI PENELITIAN}

Penelitian yang dilakukan terdiri dari beberapa tahapan yaitu:

\subsection{Pengumpulan Data}

Pengumpulan data dilakukan dengan melakukan sesi wawancara dan observasi. Wawancara dilakukan pada pihak-pihak yang telah dan akan melakukan acara pernikahan di daerah Surabaya dan dilakukan secara langsung dan tidak langsung. Dengan adanya wawancara, penelitian ini dapat mengehatuhi kebutuhan yang diperlukan user dalam sistem. Teknik observasi .dilakukan guna mengumpulkan informasi terkait dengan kriteria yang dibutuhkan dalam sistem. adapun informasi yang telah diperoleh pada gambar 1 dibawah ini :

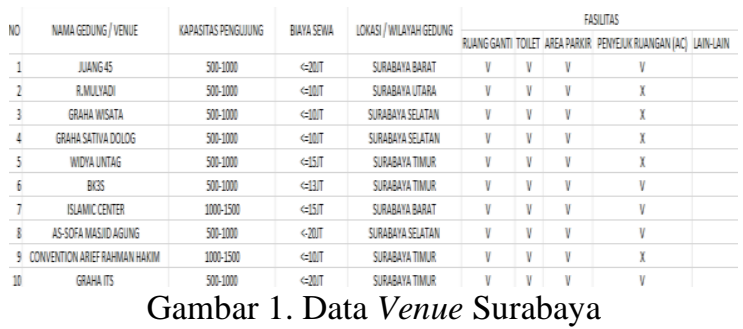

\subsection{Metode Pengembangan Sistem}

Dalam pembuatan Sistem Pendukung Keputusan menentukan Wedding Venue Menggunakan Metode TOPSIS digunakan metode SDLC (System Development Life Cycle) atau Waterfall. Karena SDLC memiliki alur kerja secara terurut, dimana setiap tahapan yang dilakukan harus dikerjakana terlebih dahulu sebelum memasuki tajapan selanjutnya. Dengan laur kerja tersebut, maka focus pengerjaan terhadap masing-masing tahapan dilakukan dengan maksimal. Berikut merupakan gambaran yang dilakukan menggunakan metode SDLC.

\section{Perancangan Sistem}

Perancangan sistem ini dibuat untuk mempermudah dalam pengerjaan hipotesis yang dibuat sebelumnya. Dimana, sistem yang dibuat dapat memberikan rekomendasi kepada user terkait pemilihan Wedding Venue yang sesuai dengan user. Perancangan yang dilakukan terkait gambaran actor yang dapat mengakses dalam sistem, alur kerja sistem, implementasi dalam sistem dan pengujian untuk mengetahui sistem yang dibuat agar sesuai dengan hipotesis.

\subsection{Usecase Diagram}

Usecase Diagram merupakan gambaran atau rangkain yang memiliki keterkaitan antara sistem dengan user. Rangkain tersebut sering disebut sebagai proses bisnis dalam pembuatan sistem. pada aplikasi Sistem Pendukung Keputusan menentukan Wedding Venue dengan Metode TOPSIS terdapat tiga aktor yaitu admin sistem, admin Venue dan user dapat dilihat pada Gambar 2.

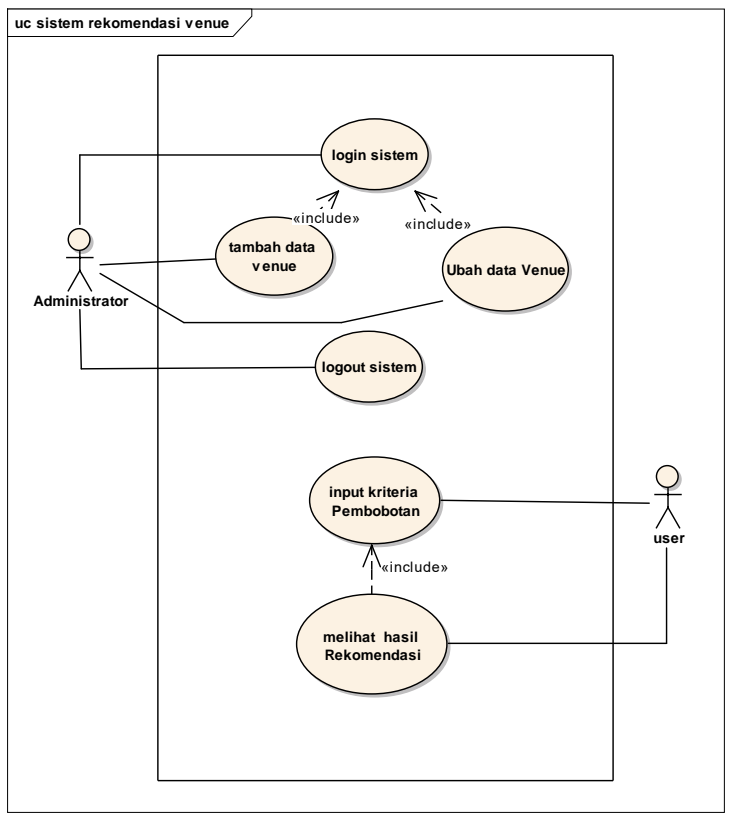

Gambar 2. Usecase Diagram

Pada gambar 2 terdiri dari tiga actor dengan bebrapa usecase yang dapat dilakukan tiap actor dalam sistem. actor admin sistem dapata melakukan login, tambah data venue dan log out. Untuk admin venue tidak jauh berbeda dengan admin sistem, namun admin venue hanya dapat mengubah data venue sesuai dengan venue yang dikelolanya. User dapat melakukan inout kriteria pembobotan dan melihat hasil rangking dari perhitungan sistem.

\subsection{Activity Diagram}

Activity diagram adalah gambaran alur kerja sistem yang harus dilakukan actor dalam sistem. alur kerja tersebut disusun sesuai berdasarkan usecase yang telah dirancang. Pada penelitian Sistem Pendukung Keputusan menentukan Wedding Venue dengan TOPSIS ini menggunakan Activity Diagram untuk menggambarkan interaksi antara user dengan sistem. berikut activity diagram sistem pendukung keputusan menentukan wedding Venue dengan metode topsis dapat dilihat pada gambar dibawah ini: 


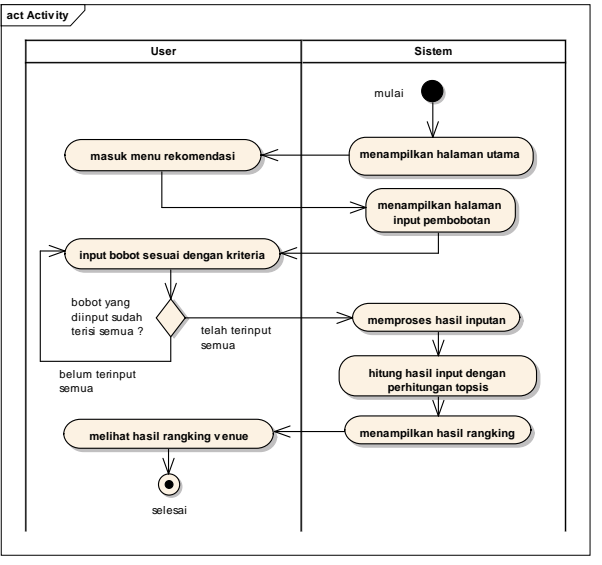

Gambar 3. Activity Diagram

Pada gambar 3 menjelaskan alur aktifitas yang dapat dilakukan oleh user. Mulai dari user masuk dalam sistem, menginput kriteria serta bobot yang diinginkan dan mendapatkan hasil rekomendasi berdasarkan metode TOPSIS

\section{Analisa dan Pembahasan}

\subsection{Implementasi Sistem}

Implementasi Sistem merupakan tahapan implementasi dari rancangan antar muka sistem dalam code dengan menggunakan PHP sebagai Bahasa pemrograman. Berikut ini merupakan gambaran halaman input bobot kriteria yang dilakukan oleh user.

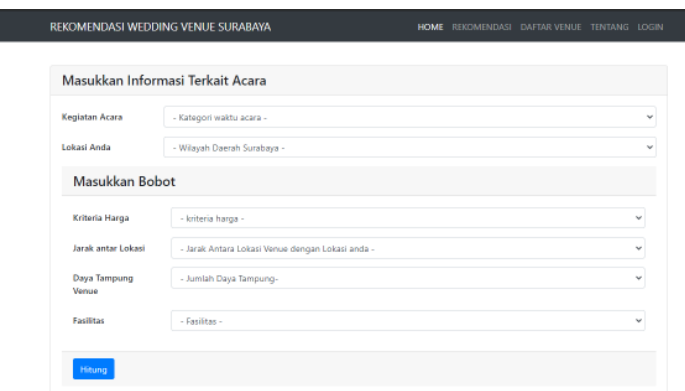

Gambar 4. Halaman Input Bobot

Pada Gambar 4 Halaman Input Bobot merupakan halaman berisi form untuk user melakukan input kriteria yang di inginkan dan bobot tiap kriteria.

Setelah melakukan input bobot dan kriteria, sistem akan melakukan perhitungan sesuai dengan metode topsis. Dengan melakukan matriks yang ternormalisasi, menghitung matriks ternormalisasi terbobot, menghitung matriks solusi ideal postif dan negatif, menghitung jarak solusi idela positif dan negatif dan menghitung alternatif terbaik dengan jarak terdekat dengan solusi ideal positif dan jarak terjauh dengan soliusi ideal negatif. Pada gambar 5 . Merupakan halaman hasil perhitungan yang ditampilkan oleh sistem.

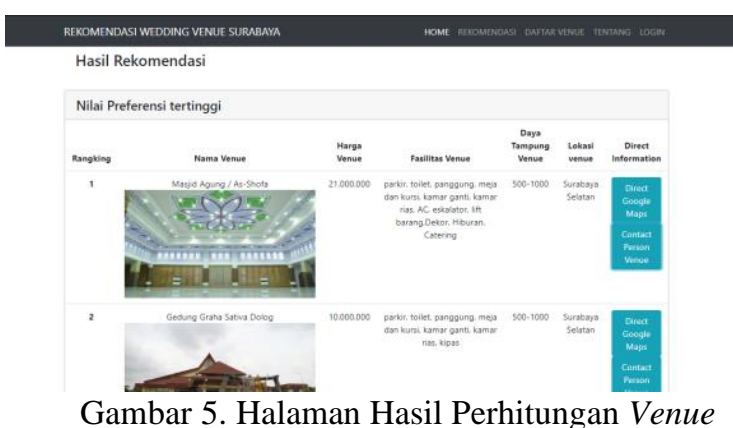

Gambar 5. Halaman Hasil Perhitungan Venue

Pada Gambar 5 menunjukan hasil perhitungan dengan venue terbaik ditampilkan dengan terurut. Hasil yang ditampilkan hanya 3 rekomendasi venue, sebagai bahan pertimbangan untuk user.

Tampilan yang diberikan berisikan infromasi terkait kriteria-kriteria yang di jadikan sebagi pertimbangan. Untuk mempermudah user mendapatkan informasi lebih, maka ditampilkan dua tombol untuk mempermudah user mengetahui lokasi venue dan contact person untuk mengubungi pihak venue terkait jadwal yang tersedia.

\subsection{Pengujian Sistem}

Pengujian sistem merupakan tahapan pengujian manual dari sistem pendukung keputusan dengan metode TOPSIS. Pengujian dalam penelitian ini dilakukan dengan 2 teknik pengujian, yaitu :

1) Pengujian Fungsional

Pengujian fungsional dilakukan untuk mengetahui sistem yang diimplementasikan memiliki fungsi yang sesuai dengan rancangan yang dibutuhkan. Pengujian ini dilakukan menggunakan teknik pengujian black box yang mengacu pada scenario usecase dengan kebutuhan fungsional yang telah ditentukan sebelumnya. Adapun hasil pengujian black box dapat dilihat pada Tabel 1.

Tabel 1. Hasil Uji Validasi Sistem dengan Black Box

\begin{tabular}{|l|l|l|l|l|}
\hline $\begin{array}{l}\text { Nomor } \\
\text { Uji } \\
\text { Valida } \\
\text { si }\end{array}$ & $\begin{array}{l}\text { Acto } \\
\mathrm{r}\end{array}$ & $\begin{array}{l}\text { Hasil Yang } \\
\text { Diinginkan }\end{array}$ & $\begin{array}{l}\text { Hasil yang } \\
\text { diperoleh }\end{array}$ & $\begin{array}{l}\text { Statu } \\
\mathrm{s}\end{array}$ \\
\hline $\begin{array}{l}\text { UV- } \\
001\end{array}$ & User & $\begin{array}{l}\text { Dapat } \\
\text { mengakses } \\
\text { halaman } \\
\text { utama } \\
\text { (home) }\end{array}$ & $\begin{array}{l}\text { Pengguna } \\
\text { dapat } \\
\text { menjalanka } \\
\text { n sistem } \\
\text { dan berada } \\
\text { pada } \\
\text { halaman } \\
\text { utama }\end{array}$ & valid \\
\hline UV- & User & $\begin{array}{l}\text { Dapat } \\
\text { mengakses } \\
\text { menu } \\
\text { rekomendas }\end{array}$ & $\begin{array}{l}\text { Pengguna } \\
\text { dapat } \\
\text { menjalanka } \\
\text { n sistem } \\
\text { dan berada } \\
\text { pada menu } \\
\text { rekomendas }\end{array}$ & valid \\
& & & \\
\hline
\end{tabular}




\begin{tabular}{|c|c|c|c|c|}
\hline $\begin{array}{l}\text { Nomor } \\
\text { Uji } \\
\text { Valida } \\
\text { si }\end{array}$ & $\begin{array}{l}\text { Acto } \\
\mathrm{r}\end{array}$ & $\begin{array}{l}\text { Hasil Yang } \\
\text { Diinginkan }\end{array}$ & $\begin{array}{l}\text { Hasil yang } \\
\text { diperoleh }\end{array}$ & $\begin{array}{l}\text { Statu } \\
\mathrm{s}\end{array}$ \\
\hline & & & $\begin{array}{l}\text { i (halaman } \\
\text { input } \\
\text { bobot) }\end{array}$ & \\
\hline $\begin{array}{l}\text { UV- } \\
003\end{array}$ & User & $\begin{array}{l}\text { Dapat } \\
\text { melihat } \\
\text { hasil } \\
\text { rekomendas } \\
\text { i dan } \\
\text { mengetahui } \\
\text { hasil } \\
\text { rangking } \\
\text { wedding } \\
\text { venue yang } \\
\text { sesuai } \\
\text { dengan } \\
\text { bobot } \\
\text { kriteria } \\
\text { yang telah } \\
\text { diinputkan }\end{array}$ & $\begin{array}{l}\text { Pengguna } \\
\text { dapat } \\
\text { melihat } \\
\text { hasil } \\
\text { rekomendas } \\
\text { i dan } \\
\text { mengetahui } \\
\text { hasil } \\
\text { rangking } \\
\text { alternative } \\
\text { (wedding } \\
\text { venue) yang } \\
\text { sesuai } \\
\text { dengan } \\
\text { bobot } \\
\text { kriteria } \\
\text { yang telah } \\
\text { diinputkan }\end{array}$ & valid \\
\hline $\begin{array}{l}\text { UV- } \\
004\end{array}$ & User & $\begin{array}{l}\text { dapat } \\
\text { mengaskses } \\
\text { informasi } \\
\text { lokasi } \\
\text { venue pada } \\
\text { halaman } \\
\text { Google } \\
\text { Maps }\end{array}$ & $\begin{array}{l}\text { Pengguna } \\
\text { dapat } \\
\text { mengakses } \\
\text { informasi } \\
\text { lokasi } \\
\text { venue pada } \\
\text { halaman } \\
\text { google } \\
\text { maps }\end{array}$ & $\begin{array}{l}\text { Vali } \\
\text { d }\end{array}$ \\
\hline $\begin{array}{l}\text { UV- } \\
005\end{array}$ & User & $\begin{array}{l}\text { Dapat } \\
\text { menampilk } \\
\text { an contact } \\
\text { person } \\
\text { pihak venue } \\
\text { yang telah } \\
\text { dikirm oleh } \\
\text { sistem susai } \\
\text { dengan } \\
\text { device yang } \\
\text { terhubung } \\
\text { dengan } \\
\text { aplikasi } \\
\text { web user. }\end{array}$ & $\begin{array}{l}\text { Pengguna } \\
\text { dapat } \\
\text { menampilk } \\
\text { an contact } \\
\text { person } \\
\text { pihak venue } \\
\text { yang telah } \\
\text { dikirm oleh } \\
\text { sistem susai } \\
\text { dengan } \\
\text { device yang } \\
\text { terhubung } \\
\text { dengan } \\
\text { aplikasi } \\
\text { web user. }\end{array}$ & $\begin{array}{l}\text { Vali } \\
\text { d }\end{array}$ \\
\hline
\end{tabular}

Berdasarkan hasil pengujian fungsioanl yang terdapat pada Tabel 1, dapat disimpulkan bahwa sistem $100 \%$ valid sesuai dengan kebutuhan fungsional yang telah dirancang.

\section{2) Pengujian Non-Fungsional}

Pengujian Non-Fungsional dilakukan untuk mengatahui perbandingan antara output sistem dengan output perhitungan manual. Pengujian ini dilakukan dengan menghitung ketepatan perhitungan Metode dengan perhitungan menggunakan Microsoft Excel.

Data alternatif yang digunakan tetap sama dengan data yang terdapat pada sistem. jika hasil peringkat yang ditampilkan dari sistem memiliki hasil yang sama dengan perhitungan manual, maka dapat dipastikan bahwa Implementasi metode TOPSIS pada Sistem Pendukung Keputusan menentukan Wedding Venue berhasil di implementasikan pada sistem. berikut ini merupakan hasil pengujian fungsional yang ditampilkan pada Tabel 2.

Tabel 2. Hasil Pengujian Validasi Algoritama TOPSIS

\begin{tabular}{|l|l|l|l|}
\hline \multirow{2}{*}{ Rangking } & \multicolumn{2}{|l|}{ Hasil Perhitungan } & \multirow{2}{*}{ Status } \\
\cline { 2 - 3 } 1 & Sistem & Manual & \\
\hline \multirow{2}{*}{2} & Masjid & Masjid & \\
& Akbar / As- & $\begin{array}{l}\text { Akbar / } \\
\text { Sofa }\end{array}$ & Valid \\
\hline \multirow{2}{*}{2} & $\begin{array}{l}\text { Graha Sofa } \\
\text { Dolog Sativa }\end{array}$ & $\begin{array}{l}\text { Graha } \\
\text { Sativa } \\
\text { Dolog }\end{array}$ & Valid \\
\hline
\end{tabular}

Tabel 2. Memaparkan hasil dari pengujian algoritam antara sistem dengan perhitungan manual bernilai valid. Maka, dapat disimpulkan bahwa hasil dari perhitungan sistem dengan perhitungan manual memiliki hasil yang akurat.

\section{Kesimpulan dan Saran}

Kesimpulan yang dapat diambil dari penulisan Sistem Pendukung Keputusan Menentukan Wedding Venue dengan Metode TOPSIS ialah:

Sistem Pendukung Keputusan menentukan Wedding Venue dengan Metode TOPSIS telah berhasil menerapkan hasil perhitungan secara benar dengan Metode TOPSIS.

Data alternatif yang digunakan pada Sistem Pendukung Keputusan menentukan Wedding Venue dengan Metode Topsis ialah penyedia jasa penyewaan Wedding Venue di Kota Surabaya, dengan empat parameter kriteria yang digunakan dalam sistem yaitu kriteria harga sewa, jumlah daya tamping, fasilitas dan jarak Hasil yang ditampilkan berupa alternatif dengan nilai preferensi tertinggi hingga terendah ditampilkan sebagai urutan rekomendasi persewaan wedding venue di Surabaya.

Hasil pengujian yang dilakukan sudah cukup akurat. Perhitungan antara sistem dengan perhitungan manual mencapi presentase akurat $98 \%$ dengan alternatif serta bobot yang sama.

Saran yang dapat dilakukan untuk penelitian selanjutnya. Dapat dilakukan gabungan metode dengan komplesitas yang sama terkait persiapan acara pernikahan dengan lokasi penelitian yang lebih luas. 


\section{Daftar Pustaka:}

Hidayati, W. (2017) 'Implementation TOPSIS on Admission Application for Karanganyar Islamic State High School', 6(1), pp. 1-10.

Iswari, V. D., Arini, F. Y. and Muslim, M. A. (2019) 'Decision Support System for the Selection of Outstanding Students Using the AHPTOPSIS Combination Method', Lontar Komputer: Jurnal Ilmiah Teknologi Informasi, 10(1), p. 40. doi: 10.24843/lkjiti.2019.v10.i01.p05.

Ningsih, E., Dedih, D. and Supriyadi, S. (2017) 'Sistem Pendukung Keputusan Menentukan Peluang Usaha Makanan Yang Tepat Menggunakan Weighted Product (Wp) Berbasis Web', ILKOM Jurnal Ilmiah, 9(3), pp. 244-254. doi: 10.33096/ilkom.v9i3.150.244-254.

Paypas, A. A., Dewi, R. K. and Brata, K. C. (2019) 'Implementasi Metode TOPSIS pada Sistem Rekomendasi Tempat Wisata Belanja di Kota Malang Berbasis Lokasi Muhammad', 3(4), pp. 3728-3732.

Sipil, D. K. dan P. (2019) 'Jumlah Penduduk Kota Surabaya'. Available at: http://dispendukcapil.surabaya.go.id/berita/48 3-ju.

Surabaya, P. K. (2015) Pembagian Kecamatan Per Wilayah.

Widjaja, M. A. (2015) 'Pengambilan Keputusan Konsumen Semarang dalam Memilih Vendor Pesta Pernikahan', Jurnal E-Komunikasi, 3(2).

Hidayati, W. (2017) 'Implementation TOPSIS on Admission Application for Karanganyar Islamic State High School', 6(1), pp. 1-10.

Iswari, V. D., Arini, F. Y. and Muslim, M. A. (2019) 'Decision Support System for the Selection of Outstanding Students Using the AHPTOPSIS Combination Method', Lontar Komputer: Jurnal Ilmiah Teknologi Informasi, 10(1), p. 40. doi: 10.24843/lkjiti.2019.v10.i01.p05.

Ningsih, E., Dedih, D. and Supriyadi, S. (2017) 'Sistem Pendukung Keputusan Menentukan Peluang Usaha Makanan Yang Tepat Menggunakan Weighted Product (Wp) Berbasis Web', ILKOM Jurnal Ilmiah, 9(3), pp. 244-254. doi: 10.33096/ilkom.v9i3.150.244-254.

Paypas, A. A., Dewi, R. K. and Brata, K. C. (2019) 'Implementasi Metode TOPSIS pada Sistem Rekomendasi Tempat Wisata Belanja di Kota Malang Berbasis Lokasi Muhammad', 3(4), pp. 3728-3732.

Sipil, D. K. dan P. (2019) 'Jumlah Penduduk Kota Surabaya'. Available at: http://dispendukcapil.surabaya.go.id/berita/48 3-ju.

Surabaya, P. K. (2015) Pembagian Kecamatan Per
Wilayah.

Widjaja, M. A. (2015) 'Pengambilan Keputusan Konsumen Semarang dalam Memilih Vendor Pesta Pernikahan', Jurnal E-Komunikasi, 3(2). 